Simulasi Kejadian Diskret Pada Perancangan Manajemen Logistik Di Unit Layanan Logistik Pertanian: Studi Kasus Di Kecamatan Pangalengan Kabupaten Bandung ( Kusnandar Dan Tomy Perdana )

\title{
SIMULASI KEJADIAN DISKRET PADA PERANCANGAN MANAJEMEN LOGISTIK DI UNIT LAYANAN LOGISTIK PERTANIAN: STUDI KASUS DI KECAMATAN PANGALENGAN KABUPATEN BANDUNG
}

\author{
Kusnandar dan Tomy Perdana
}

${ }^{1}$ Pusat Penelitian Perkembangan Iptek, Lembaga Ilmu Pengetahuan Indonesia, Jalan Gatot Subroto no 10 Jakarta

${ }^{2}$ Laboratorium Agribisnis, Fakultas Pertanian, Universitas Padjadjaran Jalan Raya Jatinangor Sumedang

\section{Email:kussrai0779@yahoo.co.id}

ABSTRAK Salah satu tantangan dalam manajemen logistik pertanian adalah karakteristik produk yang mudah rusak akibat proses biologis yang terus berlangsung setelah produk dipanen. Sementara itu di sisi lain, dinamika pasar terus berkembang dengan tuntutan kualitas tinggi dan pasokan yang kontinyu. Salah satu unit layanan logistik pertanian di Kecamatan Pangalengan Kabupaten Bandung berusaha untuk meningkatkan kualitas dan kontinuitas pasokan yang dihasilkan oleh petani anggotanya, dengan tujuan utama pasarnya adalah pasar terstruktur. Terdapat enam komoditi yang diusahakan dengan proses penanganan pasca panen yang berbeda. Penelitian ini bertujuan untuk membangun model simulasi manajemen logistik dari unit layanan logistik pertanian dengan tujuan memenuhi permintaan pasar, serta syarat waktu proses pengolahan dari setelah panen sampai pengriman tidak lebih dari 6 jam. Kajian mengambil studi kasus di unit layanan logistik pertanian di Kecamatan Pangalengan Kabupaten Bandung. Pendekatan yang digunakan adalah simulasi kejadian diskrit yang merupakan simulasi dengan perubahan status dari model simulasi terjadi pada titik-titik waktu yang diskret yang dipicu oleh kejadian.

Kata Kunci: manajemen logistik pertanian; n jenis komoditi; batas waktu penanganan; simulasi kejadian diskret.
DISCRETE EVENT SIMULATION FOR DESIGNING OF LOGISTICS MANAGEMENT IN AGRICULTURAL LOGISTICS SERVICES UNIT: A CASE STUDY OF KECAMATAN PANGALENGAN KABUPATEN BANDUNG

\begin{abstract}
Perishable characteristics due to biological process is one of the challenge in logistics management of the agricultural products. Meanwhile, the dynamics of the market continues to grow with the demands of high quality and continuous supply. A Logistics services unit located at Kecamatan Pangalengan Kabupaten Bandung seeks to increase the quality and continuity of product produced by farmer members, with the main market is structured market. Six commodities that have differences in post-harvest handling are cultivated. The aim of this research is to build a simulation model of logistics management of agricultural logistics services units in order to meet the market demand, with the terms of the processing time, from harvest to shipments, is no more than 6 hours. A logistics services unit at Kecamatan Pangalengan Kabupaten Bandung was taken as case study. Discrete event simulation, one of the simulation methode which has characterics of the change in status of the simulation model occurs at time points that are caused by discrete events, was used as an approach for building the model.
\end{abstract}

Keywords: agricultural logistics Management; commodities; processing time, discrete event simmulaion

\section{PENDAHULUAN}

Tuntutan konsumen akan kualitas produk pertanian segar semakin tinggi seiring meningkatnya kuallitas hidup, bahkan di negara maju seperti Jepang, pemilihan produk didasarkan waktu terpendek dari panen sampai dipasarkan (Iijima, et al., 1996). Sementara itu di sisi lain, sifat produk pertanian mudah rusak akibat proses biologis yang terus berlangsung setelah produk dipanen. Hal tersebut menjadi tantangan bagi pelaku dalam rantai pasok produk pertanian untuk dapat menjamin kualitas produk tetap segar dengan waktu yang pendek dari mulai panen sampai ke tangan konsumen.

Tantangan sistem logistik produk pertanian semakin tinggi di negara berkembang, hal tersebut dikarenakan sebagian besar produk dihasilkan oleh petani dengan karakteristik kepemilikan lahan sempit dan tersebar. Dengan kondisi tersebut, dalam usahataninya petani akan lebih berkonsentrasi pada pemenuhan kebutuhan sehari-hari dari pada berusaha mengembangkan pasar dan kemampuan logistiknya (Rawwas and Iyer, 2013). Oleh karena itu diperlukan lembaga pemasaran yang dapat berperan memasarkan hasil produksi petani secara kolektif, mengembangkan pasar ke arah pasar terstruktur, dan membangun sistem logistik di sentra produksi untuk mendukung pengembangan pasar tersebut.

Salah satu sub terminal agribisnis (STA) yang berlokasi di Desa Marga Mekar Kecamatan Pangalengan Kabupaten Bandung, berhasil mengembangkan pasar dengan bekerjasama dengan salah satu perusahaan pemasaran pertanian dengan tujuan pasar modern lokal dan ekspor. Dalam perjanjian kerjasama tersebut, STA Marga Mekar harus dapat memenuhi pasokan 6 (enam) jenis komoditi segar dengan kualitas dan kuantitas tertentu secara kontinyu setiap hari dengan harga yang telah disepakati bersama.

Dalam memenuhi permintaan perusahaan pemasaran tersebut, STA Marga Mekar bermitra dengan 
petani di wilayah Kecamatan Pangalengan. Peran logistik yang dilakukan oleh STA adalah mulai dari pengaturan dari jadwal tanam dan panen petani sampai dengan penanganan pasca panen yang terdiri dari pengangkutan dari lahan ke STA, pembersihan, sortasi grading, pengemasan dan transportasi ke perusahaan pemasar. Syarat produk yang dikirim adalah produk yang dipanen pada hari yang sama, sehingga tidak ada stok produk di STA. Hal tersebut menjadi tantangan STA untuk dapat mengembangkan manajemen logistik produk pertanian segar yang dapat memenuhi permintaan pasar tersetruktur dengan kualitas, kuantitas dan kontinyuitas yang telah ditentukan dengan tetap memperhatikan efisiensi agar mendapatkan keuntungan dari harga yang telah disepakati.

Penelitian ini bertujuan untuk mengembangkan perancangan manajemen logistik di STA yang menangani beberapa komoditi segar dengan routing penanganan pasca panen yang berbeda, untuk dapat memenuhi permintaan pasar terstruktur dengan batas waktu satu hari dari mulai panen sampai pengiriman. Perancangan dilakukan dengan menggunakan pendekatan simulasi kejadian diskret (discrete event simulation).

Beberapa penelitian sebelumnya mengenai pengembangan model manajemen logistik produk segar dengan memperhatikan standarad kualitas dan kuantitas sesuai permintaan pasar (Amorim, et al., 2012; Ahumada and Villalobos, 2011; Samadhi and Kusnandar, 2010) fokus pada integrasi jadwal panen dan pengolahan, tetapi tidak detail pada menajemen proses penanganan pasca panen di unit pengolahan, serta belum memodelkan batas waktu panen sampai pengiriman. Sementara itu, pendekatan simulasi kejadian diskret pada logistik produk pertanian yang mudah rusak dilakukan oleh Iannoni and Morabito (2006) yang memodelkan jadwal pengangkutan dari lahan ke tempat pengolahan, serta Cigolini, et al. (2013) yang memodelkan pemanfaatan fasilitas produksi untuk mencapai stok optmal untuk satu jenis komoditi yang mudah rusak. Model yang dikembangkan pada penelitian ini fokus pada manajemen logisitk penanganan pasca panen yang menangani 6 komoditi yang beberapa memiliki routing produksi yang berbeda, serta harus memperhatikan syarat batas waktu dari mulai panen sampai pengiriman.

\section{METODOLOGI}

Penelitian ini menggunakan pendekatan simulasi kejadian diskrit dengan bantun software ProModel. Simulasi kejadian diskret merupakan salah satu pendekatan pemodelan sistem yang cocok digunakan untuk menganalisis proses diskret, seperti sistem manufaktur, transportasi, antrian layanan, dll. Dalam simulasi kejadian diskret, perubahan status model simulasi terjadi pada waktu yang diskret yang diakibatkan oleh kejadian (fishman, 2001).

Secara umum, terdapat 7 konsep dari sistem kejadian diskret, yaitu (Fishman, 2001):

1. Work (entity), dapat berupa jobs, material atau customer yang memasuki sistem untuk diproses mendapatkan layanan.

2. Resources, dapat berupa mesin atau tenaga kerja yang memproses atau melayani entity

3. Routing, merupakan route dan urutan yang harus dilewati entity dalam suatu proses

4. Buffers, yaitu tempat menunggu entity sebelum diproses oleh resources

5. Scheduling, adalah pola waktu dari resources beroperasi

6. Sequencing, yaitu urutan dari entity yang akan diproses atau dilayani

7. Performance, merupakan kriteria ukuran kinerja sistem

Kejadian dalam suatu sistem dapat bersifat deterministic dan probabilistic (Gambar 1). Dalam kejadian deterministic, interval waktu antar kejadian akan seimbang atau jika berbeda adalah akibat dari perlakukan keputusan. Sementara dalam kejadian probabilistik, interval waktu akan bervariasi mengikuti pola distribusi tertentu (Fishman, 2001). Salah satu kelebihan dari pendekatan simulasi kejadian diskrit adalah dapat memodelkan kejadian yang bersifat probabilistik (Allen, 2011).

Kejadian probabilistik terjadi pada waktu yang tidak diketahui atau ditetapkan oleh modeler, akan tetapi masih mengikuti pola tertentu. Oleh karena itu dalam memodelkan dilakukan pendekatan pola distribusi untuk memunculkan kejadian. Munculnya suatu kejadian yang probabilistik dinyatakan dalam nilai ekspektansi (E). Untuk pola distribusi kontinyu, nilai ekpektansi $\mathrm{X}$ untuk probability distribution function $\mathrm{f}(\mathrm{x})$ tertentu, dinyatakan dengan persamaan (Allen, 2011):

$$
E(x)=\int_{-\infty}^{\infty} f(x) d x
$$

Dalam simulasi kejadian diskret, pengukuran kriteria kinerja sistem yang dapat dilakukan seperti jumlah antrian, waktu menuggu dalam antrian, waktu penyelesaian proses, jumlah produk berhasil diproses, utilitas resources dan beberapa kriteria lain yang diperlukan. 


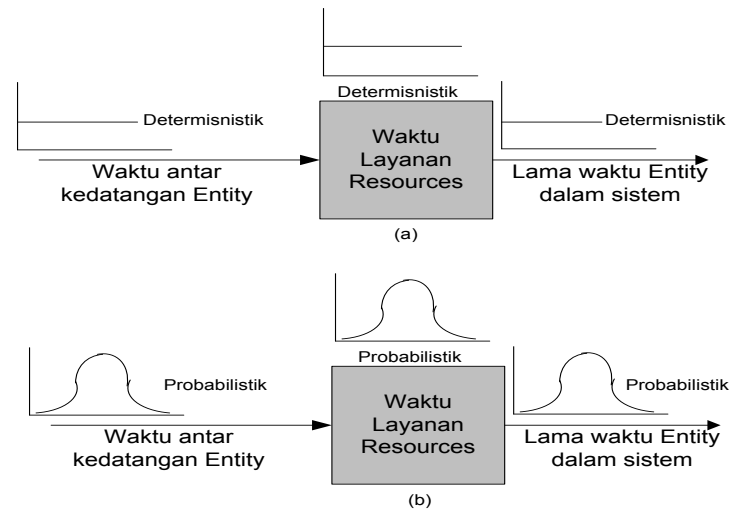

Gambar 1. Konsep Kejadian Deterministik (a) dan Probabilistik (b)

Dengan mengacu ilustrasi sistem pada Gambar 1, diasumsikan kapasitas antrian dan kedatangan tak terbatas pada interval waktu $(s, t)$ dimana $t>s>0$ dan $\mathrm{s}$ merupakan waktu warm-up, dimisalkan $\mathrm{A}_{(\mathrm{s}, \mathrm{t})}$ merupakan jumlah kedatang pada interval $(\mathrm{s}, \mathrm{t}), \mathrm{N}_{(\mathrm{s}, \mathrm{t})}$ adalah jumlah produk selesai pada interval $(\mathrm{s}, \mathrm{t}), \mathrm{B}_{(\mathrm{t})}$ adalah status resources yang bernilai 1 jika sibuk dan 0 untuk lainnya, dan $\mathrm{W}_{(\mathrm{i})}$ adalah waktu menunggu entity i, maka (Allen, 2011):

$$
\begin{aligned}
& \mathrm{A}_{(\mathrm{s}, t)}=A_{(0, t)}-A_{(0, s)} \\
& \mathrm{N}_{(\mathrm{s}, t)}=N_{(0, t)}-N_{(0, s)} \cdots . . \\
& \mathrm{A}_{(0, t)}-N_{(0, t)}=Q_{(t)}-B_{(t)}
\end{aligned}
$$

Rata-rata jumlah kedatangan:

$\overline{\mathrm{A}}_{(\mathrm{s}, \mathrm{t})}=\frac{A_{(s, t)}}{t-s}$

Rata-rata produk selesai diproses:

$$
\overline{\mathrm{N}}_{(\mathrm{s}, \mathrm{f})}=\frac{N_{(s, t)}}{t-s}
$$

Rata-rata panjang antrian:

$$
\overline{\mathrm{Q}}_{(\mathrm{s}, \mathrm{t})}=\frac{1}{t-s} \int_{s}^{t} D(u) d
$$

Rata-rata utilitas resources:

$$
\overline{\mathrm{B}}_{(\mathrm{s}, t)}=\frac{1}{t-s} \int_{s}^{t} B(u) d
$$

Rata-rata waktu menunggu:

$$
\overline{\mathrm{W}}_{(\mathrm{s}, \mathrm{g}}=\frac{1}{N_{(s, t)}} \sum_{i=N_{(o, s)}+1}^{N_{(0, t)}} W_{i}
$$

Tahapan penelitian pada penelitian ini adalah sebagai berikut (mengacu pada ProModel Corporation. 2011)

1. Perencanaan studi

Studi dilakukan untuk merancang manajemen logistik di STA Marga Mekar yang mengelola 6 komoditi segar untuk memenuhi permintaan pasar terstruktur, dengan syarat dari waktu setelah panen sampai pengiriman tidak lebih dari 6 jam.

2. Definisi sistem

Melakukan observasi ke lokasi STA untuk mendapatkan informasi tahapan proses produksi untuk setiap jenis komoditi, waktu di setiap stasiun produksi, kapasitas produksi, serta alat dan tenaga kerja. Akan tetapi karena produksi belum berjalan secara kontinyu maka informasi tersebut ditanyakan pada pengelola yang telah berpengalaman dalam penanganan pasca panen produk pertanian.

3. Membangun model

Model yang dibangun dibatasi hanya pada lingkup aktivitas di STA dari mulai hasil panen datang, pemrosesan, sampai dengan pengiriman ke pasar. Model simulasi ini dibuat dengan menggunakan software komputer Pro Model. Setelah model terbangun dilakukan verifikasi dan validasi. Verifikasi dilakukan dengan menguji apakah model dapat berjalan tanpa adanya eror. Setelah verifikasi selesai, dilakukan validasi, karena sistem nyatanya belum berjalan secara kontinyu, maka tidak dapat dilakukan perbandingan data hasil simulasi dengan data real. Oleh karena itu validasi dilakukan dengan analisis sensitivitas dengan mencoba pada beberapa interval waktu simulasi, kemudian dilihat kesesuaian hasil dengan logika perhitungan manual.

4. Menjalankan Percobaan

Setelah model dianggap valid, maka mencoba beberapa scenario, yaitu mencoba beberapa kombinasi resources yang dapat menyelesaikan proses penanganan pasca panen sesuai volume permintaan dengan jarak waktu yang ditentukan, dengan tetap memperhatikan utilitas resources.

5. Analisa Hasil

Hasil simulasi dianalisis untuk menghasilkan rancangan manajemen logistic terbaik. Selain itu dilakukan juga analisis keterbatasan dari model yang telah dibangun.

\section{HASIL DAN PEMBAHASAN}

\section{Sistem Logistik di STA Marga Mekar}

Komoditi yang diusahakan oleh unit layanan logistik STA Marga Mekar terdiri dari kentang, wortel, tomat, brokoli, kol dan sawi. Seluruh komoditi tersebut dipanen pada pagi hari, kemudian dikirim ke STA untuk diproses mulai dari pembersihan, sortasi, pengemasan 
sampai dengan pengiriman ke pasar tujuan. Batas waktu prosuk sampai ke pasar tujuan adalah malam hari pada hari yang sama, sehingga seluruh produk harus selesai dikemas pada sore hari, karena pasar tujuan berada di luar kota.

Untuk proses penangan pasca panen, STA Marga Mekar akan membagi tempat kerja berdasarkan jenis proses yang terdiri dari 7 , yaitu tempat penerimaan hasil panen, trimming, cuci, pembersihan, sortasi grading, pengemasan, penyimpanan sementara untuk produk lolos sortasi dan grading, serta penyimpanan sementara untuk produk yang tidak lolos sortasi dan grading. Tidak semua komoditi memiliki route proses penanganan yang sama karena terkait karakteristik produk. Route proses penangan tiap produk disajikan pada Gambar 2.

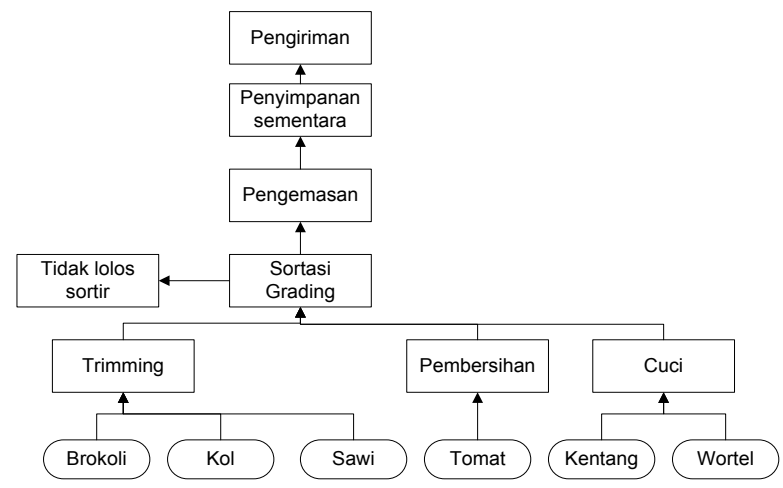

Gambar 2. Route Proses Penanganan Setiap Komoditi

Seluruh proses penangan pasca panen di STA Marga Mekar dilakukan secara manual, karena belum tersedianya mesin yang dapat memproses secar otomatis. Oleh karena itu dalam setiap stasiun kerja memerlukan minimal satu tenaga kerja.

\section{Pemodelan Simulasi Kejadian Diskrit Untuk Perancangan Manajemen Logistik di STA Marga Mekar}

Model simulasi yang dikembangkan pada manajemen logistik di STA Marga Mekar adalah untuk melihat proses penanganan dalam satu hari produksi. Hal tersebut untuk mengantisipasi permintaan pasar terstruktur yang mensyaratkan kontinyuitas pasokan setiap hari. Sesuai dengan sifatnya, model simulasi kejadian diskrit cocok digunakan dalam manajeman logistik untuk level operasional (Tako and Robinson, 2012).

Lingkup model yang dibangun dibatasi pada sistem penanganan mulai hasil panen datang sampai dikirim ke pasar.

Asumsi yang digunakan dalam membentuk model ini adalah:

1. Semua resources (tenaga kerja) dapat mengerjakan seluruh jenis aktivitas penanganan pasca panen.

2. Semua resources (tenaga kerja) memiliki kemampuan yang sama sehingga tidak ada perbedaan waktu dalam menyelesaikan suatu proses

3. Seluruh komoditi datang secara bersamaan sehingga keputusan sequencing dapat dilakukan dari awal.

4. Waktu set up setiap stasiun kerja pada pergantian setiap komoditi sama

Aturan yang dirancang dalam model ini adalah:

1. Seluruh produk harus selesai diproses dalam jangka waktu 6 jam (asumsi selesai panen jam 10.00 WIB dan harus dikiirm ke pasar tujuan maksimal jam 16.00 WIB).

2. Komoditi (entity) dimodelkan per satuan unit $\mathrm{kg}$

3. Urutan pengerjaan komoditi mengikuti aturan FIFO (first in first out)

4. Pemrosesan di satu stasiun kerja (location) diselesaikan per jenis komoditi, sehingga tidak bercampur dalam waktu yang bersamaan

5. Terdapat waktu set up di setiap stasiun kerja (location) pada setiap pergantian komoditi selama 5 menit.

Berdasarkan aturan tersebut, maka flow chart model simulasi yang dibangun seperti pada Gambar 3 .

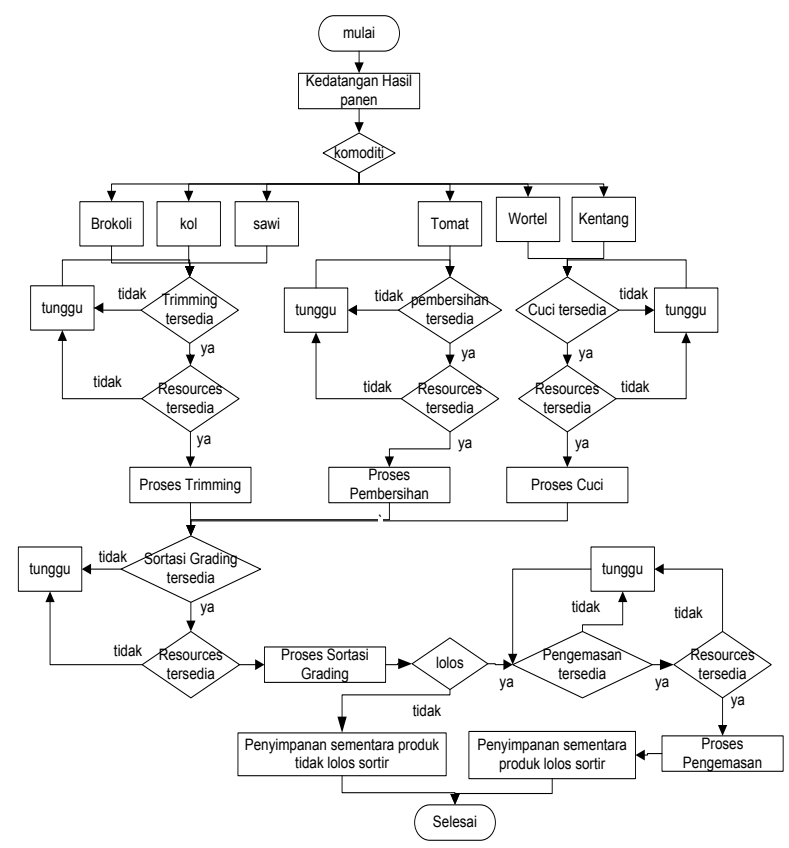

Gambar 3. Flow Chart Model Simulasi

Routing penangan pasca panen dalam sistem ini ada yang bersifat seri dan paralel. Untuk routing yang bersifat seri akan terjadi saat satu stasiun kerja (location) sibuk location berikutnya menunggu, atau ketika location berikutnya sibuk location sebelumnya telah selesai dan idle. Dalam pengoperasiannya, apabila satu location dipegang khusus oleh satu resource, maka akan terjadi inefisiensi resources. Oleh karena itu dalam model ini aturannya tidak ada resources yang khusus menangani satu stasiun kerja tertentu, tetapi 
semua resources dapat melakukan setiap aktivitas pekerjaan. Dalam model yang dikembangkan, setiap resources akan mengidentifikasi setiap entity yang siap untuk diproses pada stasiun kerja tertentu. selesai mengerjakan satu komoditi di satu stasiun kerja, resources akan mengidentifikasi kembali entity lain yang harus diproses baik pada stasiun kerja yang sama atau stasiun kerja lainnya dengan aturan memilih entity yang memiliki waktu tunggu paling lama. Oleh karena itu resourcesakan berpindah dari stasiun kerja yang diproses pertama ke stasiun kerja berikutnya.

Dalam model yang dikembangkan ini juga memiliki aturan bahwa pengerjaan dilakukan per komoditi. Ketika satu location mulai mengerjakan satu komoditi, maka akan dilakukan sampai komoditi tersebut habis seluruhnya diproses, tidak bercampur-campur. Untuk dapat memodelkannya maka komoditi sejumlah yang telah ditentukan pada titik tertentu dianggap sebagai satu batch, tetapi pada titik tertentu berikutnya daoat dipisahkan kembali. Untuk dapat memenuhi aturan tersebut digunakan perintah GROUP dan UNGROUP.

Data permintaan yang digunakan dalam proses simulasi (hipotetik) disajikan pada Tabel 1. Sementara data waktu pengerjaan setiap komoditi pada setiap proses disajikan pada Tabel 2 .

Tabel 1. Data Permintaan Tiap Komoditi

\begin{tabular}{lrrrr}
\hline Komoditi & \multicolumn{2}{c}{$\begin{array}{c}\text { Proporsi } \\
\text { Grade Pasar Kebutuhan/bl Kebutuhan } \\
\text { Terstruktur }\end{array}$} & $\begin{array}{c}\text { Kebutuhan } \\
\text { n (kg) }\end{array}$ & $\begin{array}{c}\text { Perhari } \\
\text { Panen }\end{array}$ \\
\hline Kentang & $70 \%$ & 2 & 67 & 96 \\
Wortel & $50 \%$ & 8 & 267 & 534 \\
Tomat & $75 \%$ & 2 & 67 & 89 \\
Brokoli & $50 \%$ & 1,5 & 50 & 100 \\
Kol & $50 \%$ & 1,5 & 50 & 100 \\
Sawi & $50 \%$ & 1,5 & 50 & 100 \\
\hline
\end{tabular}

Tabel 2. Data Waktu Proses Tiap Komoditi

\begin{tabular}{|c|c|c|c|c|c|}
\hline \multirow[b]{2}{*}{ Komoditi } & \multicolumn{5}{|c|}{ Waktu (menit/Kg) } \\
\hline & Trimming & Pembersihan & Cuci & $\begin{array}{l}\text { Sortasidan } \\
\text { Grading }\end{array}$ & Pengemasan \\
\hline Kentang & & - & $\begin{array}{l}\mathrm{n}(0.39, \\
0.043)\end{array}$ & $\mathrm{n}(0.39,0.043)$ & $\mathrm{n}(0.77,0.086)$ \\
\hline Wortel & - & - & $\begin{array}{l}\mathrm{n}(0.54, \\
0.06)\end{array}$ & $\mathrm{n}(0.54,0.06)$ & $\mathrm{n}(1.08,0.12)$ \\
\hline Tomat & - & $\mathrm{n}(0.9,0.1)$ & - & $\mathrm{n}(0.9,0.1)$ & $\mathrm{n}(1.8,0.2)$ \\
\hline Brokoli & $\mathrm{n}(1.35,0.15)$ & & - & $\mathrm{n}(1.35,0.15)$ & $\mathrm{n}(2.7,0.3)$ \\
\hline Kol & $\mathrm{n}(1.35,0.15)$ & & - & $\mathrm{n}(1.35,0.15)$ & $\mathrm{n}(2.7,0.3)$ \\
\hline Sawi & $\mathrm{n}(1.35,0.15)$ & & - & $\mathrm{n}(1.35,0.15)$ & $\mathrm{n}(2.7,0.3)$ \\
\hline
\end{tabular}

Keterangan: $\mathrm{n}=$ distribusi normal (rata-rata, standard deviasi)

Pada saat simulasi, karena sistem yang dimodelkan dibatasi pada aktivitas proses di STA dan kedatangan seluruh komoditi diasumsikan bersamaan, maka harus ditentukan komoditi mana yang pertama diproses. Untuk hal tesebut, langkah pertama adalah mengkelompokan komoditi yang memiliki routing yang sama, yaitu kentang dan wortel, serta brokoli, kol dan sawi, sementara tomat memiliki routing yang berbeda sendiri. kemudian untuk komoditi-komoditi dengan routing yang sama ditentukan mana yang diproses terlebih dahulu. Karena waktu setup setiap pergantian komoditi dianggap sama, maka penentuan urutan proses komoditi tidak akan berpengaruh pada total waktu penyelesaian. Akan tetapi akan berpengaruh pada waktu produk menunggu (flow time), di mana untuk komoditi segar kecepatan penanganan sangat berpengaruh terhadap kualitas. Menurut Baker (1974), untuk meminimasi flow time digunakan aturan pengurutan berdasarkan waktu proses terpendek (shortest processing time atau SPT). Dalam model ini, untuk setiap kelompok komoditi dilakukan penentuan urutan berdasartkan SPT pada stasiun kerja pertama. Untuk ilustrasi simulasi model dapat dilihat pada Gambar 4.

\section{Skenario dan Analisis Hasil Simulasi}

Dari model simulasi yang telah terbangun, kemudian dilakukan perancangan skenario untuk mendapatkan hasil sesuai dengan tujuan, yaitu pemenuhan permintaan pasar terstruktur sesuai dengan permintaan dengan tetap memperhatikan efisiensi jumlah lokasi dan resources. Perancangan skenario dapat ditentukan dengan perubahan parameter, struktur atau keduanya. Penentuan tersebut dilakukan secara manual oleh percanangnya, karena sesuai dengan sifatnya, model simulasi sangat berguna untuk sistem yang sangat kompleks tetapi memiliki kelemahan dalam mencapai scenario optimal (Hagendorf and Pawletta, 2011). Pada penelitian ini perancangan scenario dilakukan hanya pada parameter, yautu dengan mengubah kombinasi dari jumlah setiap lokasi dan resources.

Pada scenario pertama ditentukan setiap lokasi berjumlah satu dan dikerjakan oleh satu resources sehingga resources berjumlah 6 . Kemudian setelah disimulasikan ternyata belum dapat memenuhi permintaan pasar dengan batas waktu pengerjaan yang telah ditentukan yaitu selama 6 jam. Kemudian diidentifikasi location mana yang menjadi bottleneck dan perlu ditambah dengan melihat jumlah entity yang berhasil dikerjakan dan nilai utilisation. Untuk identifikasi resources dilihat pada nilai utilization, apabila masih rendah maka tidak perlu ditambah. Hal tersebut terus dilakukan sampai mendapatkan hasil yang terbaik. Scenario dan hasilnya disajikan pada Tabel 3. 


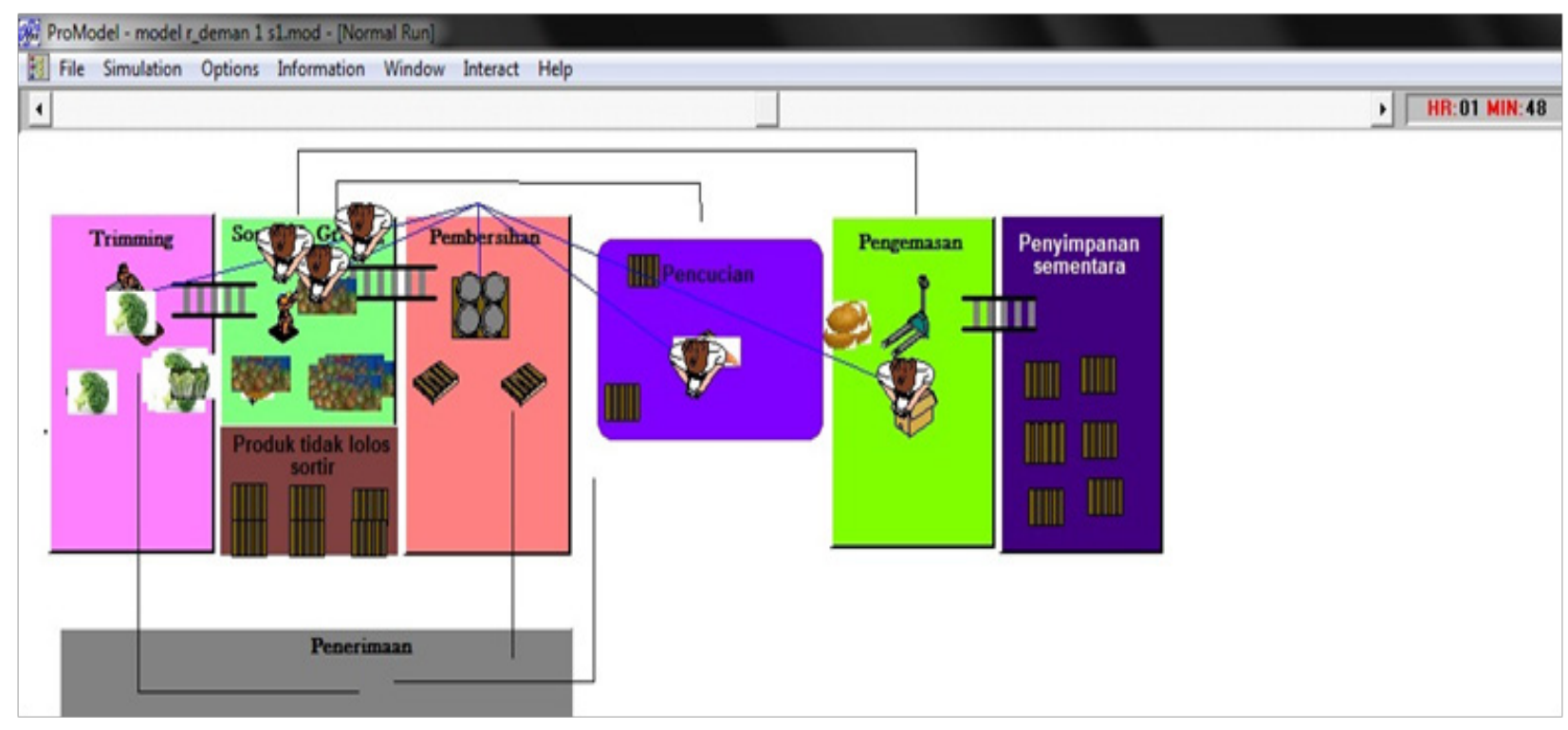

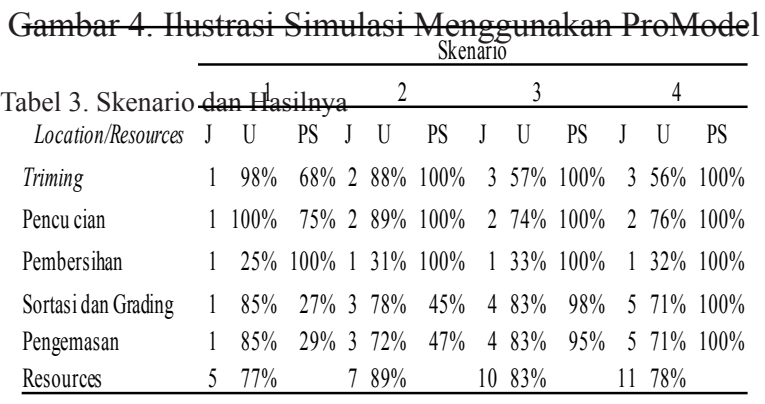

Keterangan: J (Jumlah); U (Utilitas); PS (Produk Terselesaikan)

Berdasarkan tabel 3, scenario 4 dengan jumlah location trimming 3 , pencucian 2 , pembersihan 1 , sortasi grading 5, pengemasan 5, dan resources 11, merupakan scenario terbaik yang dapat memenuhi permintaan pasar terstruktur. Skenario tersebut juga memiliki efisiensi cukup tinggi yang dapat dilihat dari utilization dari resources yang mencapai $78 \%$. Sesungguhnya penentuan skenario yang dilakukan tersebut merupakan salah satu metode untuk menyelesaikan masalah trade off antara mempertahankan kualitas produk tetap segar dengan penambahan biaya akibat penambahan sumberdaya yang merupakan faktor kunci keberhasilan penanganan produk segar (Ahumada and Villalobos, 2011).

\section{SIMPULAN}

1. Dengan pendekatan simulasi kejadian diskret dapat dirancang skenario terbaik untuk manajemen logistik komoditi pertanian segar di unit layanan logistik pertanian, untuk memenuhi permintaan pasar terstruktur sesuai dengan standar yang ditetapkan.

2. Pemodelan resources dinamis yang dapat mengerjakan seluruh aktivitas proses, dapat meningkatkan utilization resources yang berarti meningkatkan efisiensi.

3. Penentuan perubahan kombinasi jumlah stasiun kerja (location) dan resources pada saat permintaan belum terpenuhi, dapat dilakukan dengan melihat jumlah entity yang berhasil diproses dan nilai utilization untuk mengidentifikasi bottleneck dari proses aktivitas logistik.

\section{KETERBATASAN DAN SARAN PENGEMBANGAN MODEL}

1. Model yang dikembangkan ini lingkupnya dibatasi hanya pada aktivitas logistik di STA dari mulai hasil panen datang sampai produk dikemas dan siap dikirm, untuk pengembangan berikutnya dapat diintegrasikan dengan model jadwal panen dan route pengangkutan hasil panen dari kebun yang lokasinya tersebar.

2. Pergerakan komoditi pada model ini masih otomatis berjalan sendiri, untuk selanjutnya dapat dimodelkan pengangkutan yang dilakukan oleh tenaga kerja dengan memperhitungkan kapasitas sekali angkut dan lama pengangkutan.

3. Data yang digunakan dalam model ini bersumber dari praktisi karena STA belum beroperasi secara kontinyu, untuk kepentingan aplikasi, pada saat STA telah beroperasi data harus didapatkan dari pengukuran langsung agar mendapatkan hasil yang akurat.

\section{DAFTAR PUSTAKA}

Ahumada, O., J. R. Villalobos. 2011. Operational model for planning the harvest and distribution of perishable agricultural products. Int. J. Production Economics 133 (2011) 677-687

Allen, T. T. 2011. Introduction to Discrete Event 
Simulation and Agent-based Modeling Voting Systems, Health Care, Military, and Manufacturing. Springer-Verlag London Limited. Amorim, P., H. O.G Unther, B. Almada-Lobo. 2012. Multi-objective integrated production and distribution planning of perishable products. Int. J. Production Economics 138 (2012) 89-101

Baker, K. R., \& D. College. 1974. Introduction to Sequencing and Scheduling. John Wiley \& Sons, New York

Cigolini, R., M. Pero, T. Rossi, A. Sianesi. Linking supply chain configuration to supply chain performance: A discrete event simulation model. Simulation Modelling Practice and Theory 40 (2013) 1-11

Fishman, G. S. 2001. Discrete-Event Simulation Modeling, Programming, and Analysis. Springer Science+Business Media, LLC, New York

Hagendorf, O., T Pawletta. 2011. A Framework for Simulation-based Structure and Parameter Optimization of Discrete-Event System. In Mosteman, P. J. (eds). Discrete-Event Modeling and Simulation. Theory and Applications. Series Editor. CRC Press Taylor \& Francis Group Boca Raton

Iannoni, A. P., R. Morabito. 2006. A discrete simulation analysis of a logistics supply system. Transportation Research Part E 42 (2006) 191-210

Iijima, M., S. Komatsub., S. Katoh. 1996. Hybrid just-in-time logistics systems and information networks for effective management in perishable food industries Int. J. Production Economics 44 (1996) 97-103

ProModel Corporation. 2011. ProModel 2011 User Guide. ProModel Corporation

Samadhi, T. M. A., \& Kusnandar. 2010. Development of Model for Integrated Harvesting and Processing Scheduling of Strawberry for Maximising Profit. Proceedings of The 2nd International Conference on Logistics and Transport \& The 1st International Conference on Business and Economics, 16-18 December 2010.

Tako, A.A., S. Robinson. 2012. The application of discrete event simulation and system dynamics in the logistics and supply chain context. Decision Support Systems 52 (2012) 802-815 